\title{
Research on Water Conservancy Modernization Based on Multi- index Comprehensive Evaluation
}

\author{
Zhou Jiahong $^{1,2^{*}}$, Liu Lijun ${ }^{1,2}$, Chen Yifan ${ }^{1,2}$ \\ ${ }^{1}$ Zhejiang Institute of Hydraulic and Estuary, Hangzhou, Zhejiang, China \\ ${ }^{2}$ Key Laboratory for Water Disaster Prevention and Mitigation of Zhejiang, Hangzhou, Zhejiang, China
}

\begin{abstract}
The modernization of water conservancy is an important part of socialist modernization. The research and analysis of the evaluation index of water conservancy modernization will help to define the direction and goal of modernization at a higher level in the future. Taking Hangzhou as an example, 41 comprehensive indexes in 7 categories were adopted as the quantitative evaluation indexes of water conservancy modernization in Hangzhou, and the comprehensive evaluation method of multiple indexes was used to analyze and calculate the level of water conservancy modernization in Hangzhou.
\end{abstract}

\section{Introduction}

Water conservancy modernization is an important part of socialist modernization. With the development of society, the modernization of water conservancy has gradually attracted the attention of all sides, and the modernization of water conservancy has been extensively studied at home and abroad.

The general conception of water conservancy modernization mainly includes three aspects: concept modernization, production technology and equipment modernization and water conservancy management modernization. Some developed countries such as the United States and Japan put forward and practiced water conservancy modernization as early as the 1990s. The process of water conservancy modernization in developed countries has roughly experienced four stages: the period of water conservancy construction with single objective development as the main object, the period of large-scale water conservancy construction with multi-objective development as the main object, the period of comprehensive management with water regulations and modern management as the center, and the period of sustainable development with the harmonious coexistence of human and water. The research on water conservancy modernization started late in China, but various explorations have been carried out at present. The Ministry of Water Resources proposed that by 2050, water conservancy modernization will be achieved in an allround way, and water security capacity will be improved in an all-round way. Department of Water Resources in Zhejiang Province also proposed that water ecological protection and construction should be strengthened in an all-round way by 2035 , and by the middle of this century, the construction and management of water conservancy projects and services related to water conservancy will comprehensively improve, and achieve modernization of water conservancy projects at a high level.

Taking Hangzhou as an example, this paper analyzes the modernization level of water conservancy in Hangzhou.

\section{Construction of index system}

The evaluation system of water conservancy modernization is a dynamic and relative evaluation standard to measure the level of water conservancy modernization in a certain period. The selection of evaluation index of water conservancy modernization should reflect the achievement, current level and existing problems of water conservancy construction in a region as comprehensively as possible.

The index system of Hangzhou water conservancy modernization is divided into target layer, criterion layer and index layer. Among them, the target layer reflects the realization of the water conservancy modernization level of Hangzhou, namely the water conservancy modernization level; The criteria layer respectively includes 7 macro development indicators, such as flood control and drainage, water resources guarantee and utilization, water eco-environment, agricultural irrigation and drainage system, water under standard management according to law, intelligent water conservancy construction, and water conservancy science and technology talents. These seven aspects determine the relationship between water conservancy development and economic and social development. Several indexes are set under each criterion layer, which mainly reflect the

* Corresponding author:jh-kidd@qq.com 
concrete physical quantity of water conservancy modernization construction and are the foundation of the whole evaluation system. This index system is mainly used to evaluate the modernization level of water conservancy in Hangzhou. It involves a complete set of evaluation indexes, and takes comprehensive, systematic, hierarchical, comparable, independent and operable into consideration as a whole. Based on the seven aspects of the criterion layer, 41 comprehensive indexes in 7 categories were finally extracted as the quantitative evaluation indexes of Hangzhou water conservancy modernization.

\section{Evaluation methods and criteria}

\subsection{Determination of index weight}

Weight is a comprehensive measure of subjective evaluation and objective reflection of relative importance of target or index in decision-making. The determination of weight directly affects the result of evaluation. Therefore, it is very important to choose the weight determination method suitable for comprehensive evaluation of water conservancy modernization.

In order to eliminate or reduce the subjective and objective method respectively the impact of the result of the decision, the realization degree of quantitative indicators to the status quo in this report as sample, using the fuzzy cluster cyclic iteration method, give full consideration to water conservancy modernization and target values for the evaluation of the impact of change, adjust the weight of each index. On this basis, combined with the present situation, characteristics and characteristics of Hangzhou water conservancy development, the optimal weight obtained by the algorithm is consulted by experts to further improve the weight assignment.

\subsection{Evaluation method}

The multi-index comprehensive evaluation method is selected to evaluate the modernization level of water conservancy. Multi-index comprehensive evaluation method is a effective approach to solve the difficulties of different evaluation indexes, this method is able to reflect the evaluation of multiple indexes of information together, things get a comprehensive index, in order to reflect the whole situation of the evaluation of things, and horizontal and vertical comparison, make both the comprehensive evaluation, and comprehensive.

The comprehensive evaluation index of water conservancy modernization is calculated according to the following formula:

$$
\begin{aligned}
& N_{k}=\sum_{i}^{m_{k}} b_{k i} z_{k i} \\
& N=\sum_{i}^{n} a_{k} N_{k}
\end{aligned}
$$

Substituting Equation (1) into Equation (2), the comprehensive index model of water conservancy modernization can be obtained:

$$
N=\sum_{i}^{n} a_{k} N_{k}=\sum_{i}^{n} a_{k} \sum_{i}^{m_{k}} b_{k i} z_{k i}
$$

$\mathrm{N}$-- comprehensive evaluation index of water conservancy modernization;

$N_{k}$-- The value of the evaluation index of the $\mathbf{k}$ criterion layer;

$\mathrm{n}$-- Total number of criteria layer indicators;

$a_{k}$-- The index weight of the $\mathbf{k}$ criterion layer;

$b_{k i}$-- The weight of the $\mathbf{i}$ evaluation index in the $\mathbf{k}$ criterion layer evaluation index;

$z_{k i}$-- The value of the $\mathbf{i}$ evaluation index in the $\mathbf{k}$ criterion layer evaluation index;

$m_{k}--$ The number of indicators in the $\mathbf{k}$ criterion layer evaluation index.

The calculation of each evaluation index shall be handled according to the following formulas and principles:

(1) For positive indicators

$N_{k i}=Z_{k i} / Z_{s k i}$

In the formula:

$N_{k i}$-- The standardized value of an index;

$Z_{\text {ski }}$-- The targe value of an indicator.

(2) For the negative indicator

$N_{k i}=Z_{s k i} / Z_{k i}$

If the status quo value of the positive indicator is greater than or equal to the reference value, and the status quo value of the negative indicator is less than or equal to the reference value, the score of the indicator is full score 1.

Table 1. Evaluation index weight.

\begin{tabular}{|c|c|c|}
\hline & evaluation index & weight \\
\hline 1 & $\begin{array}{c}\text { flood control and drainage } \\
\text { capacity }\end{array}$ & 0.18 \\
\hline 2 & $\begin{array}{c}\text { water resources security and } \\
\text { utilization }\end{array}$ & 0.15 \\
\hline 3 & $\begin{array}{c}\text { water ecological } \\
\text { environment }\end{array}$ & 0.15 \\
\hline 4 & $\begin{array}{c}\text { irrigation and drainage } \\
\text { system }\end{array}$ & 0.07 \\
\hline 5 & $\begin{array}{c}\text { water in accordance with } \\
\text { the law }\end{array}$ & 0.2 \\
\hline 6 & $\begin{array}{c}\text { smart water conservancy } \\
\text { construction }\end{array}$ & 0.15 \\
\hline 7 & $\begin{array}{c}\text { water conservancy science } \\
\text { and technology talents }\end{array}$ & 0.1 \\
\hline
\end{tabular}

\subsection{Evaluation criteria}

According to the research results at home and abroad, the development process of water conservancy modernization at different development levels is divided into five stages: preparation, beginning, initial stage, middle stage and basic realization. The weighted total of the comprehensive realization degree of each index reaches more than $90 \%$, which can be judged to reach the standard of basic modernization comprehensively.The specific requirements of comprehensive evaluation value at each stage of development are as follows:

Table 2. Evaluation criteria.

\begin{tabular}{|c|c|c|}
\hline & Stage of development & Criteria \\
\hline 1 & Preparation stage & $\mathrm{N}<50$ \\
\hline
\end{tabular}




\begin{tabular}{|c|c|c|}
\hline 2 & Initial stage & $50 \leqslant \mathrm{~N}<60$ \\
\hline 3 & Initial development stage & $60 \leqslant \mathrm{~N}<70$ \\
\hline 4 & Intermediate development stage & $70 \leqslant \mathrm{~N}<85$ \\
\hline 5 & Basic realization stage & $85 \leqslant \mathrm{~N}<90$ \\
\hline 6 & Higher level realization stage & $\mathrm{N} \geqslant 90$ \\
\hline
\end{tabular}

\section{Evaluation of water conservancy modernization}

Based on the water resources census data and the annual statistical data published in the water resources bulletin and annual statistical report, 2017 is taken as the baseline year for the current situation. According to the statistical value, target value and index weight of all levels, the index values of the criterion layer are calculated successively. The score of flood control and drainage capacity is 80.0, which belongs to the "medium-term development stage". The score of water resources security and utilization is 79.5, which belongs to the "medium-term development stage". The score of water ecological environment is 75.6, which belongs to "medium development stage". The score of irrigation and drainage system was 87.3 , which reached the "basic realization stage". The score of water in accordance with the law is 75.9 , belonging to the "medium development stage"; The score of smart water conservancy construction is 58.3 , which belongs to the "initial stage". The score of water conservancy science and technology talents is 81.3 , which belongs to the "medium-term development stage".

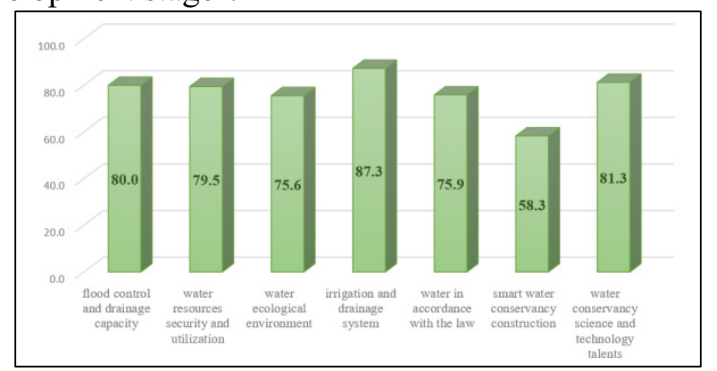

Fig. 1. Evaluation results of water conservancy modernization development level.

According to the above analysis, the current level of water conservancy modernization in Hangzhou is 75.8, which is in the "medium-term development stage".

\section{Conclusion}

Water conservancy modernization is the foundation of economic and social modernization in Zhejiang Province. Water conservancy, as an infrastructure and basic industry, should advance moderately in the whole process of modernization construction. Scientific construction of the characteristic index system of water conservancy modernization in Hangzhou will certainly promote the support and guarantee capacity of water conservancy for economic and social development, and support Hangzhou to take the lead in building a moderately prosperous society in all respects and basically realizing modernization with water conservancy modernization.

\section{Acknowledgements}

This work was financially supported by the National Natural Science Foundation of China (51609213)

\section{References}

1. Zhang C., Qiao H., Wang L., Sun L., The Water Conservancy Modernization of Developd Countries and Its Enlightenment to China, China Rural Water and Hydropower, 2015,2:47-50.

2. Huang K., Du W., Lu Y., The Construction Idea of Index System of Water Conservancy Modernization in Ningbo, Water Resources Planning and Design, 2019,7:10-12.

3. Guo L., Li P., Li K., Guan G., Research on Evaluation Index System of Water Conservancy Modernization in Maanshan, Guangdong Water Resources and Hydropower, 2016,11:51-53.

4. Xie D., Discussion on The Construction of Evaluation Index System of Water Conservancy Project Management Modernization, Engineering Management, 2018,12:101-102.

5. Sun S. Yu J. Yang H. Liu Y., Research on water conservancy modernization system based on intelligent brain, China Water Resources, 2020,19:52-55. 